analysis, to which the other authors contributed. ES, SL, and $\mathrm{ADO}$ led the writing of the paper, to which the other authors contributed. ES and SL are guarantors.

Funding: Funding was provided by the Alliance for Health Policy and Systems Research (ID-3.115), German Technical Development (PN: 95.2068.5-001.00), and the European Commission funded Practihc (pragmatic randomised trials in health care) project (ICA4-CT-2001-10019). Additional funding for the study collaborators was provided by the Medical Research Council of South Africa. The study sponsors approved the study design but played no part in the collection, analysis, and interpretation of data; in the writing of the report; or in the decision to submit the paper for publication.

Competing interests: None declared.

Ethical approval: This study was approved by the Comite Nacional de Bioética para a Saúde in Mozambique, the Medical Research Council of Zimbabwe, and the ethics committees of the London School of Hygiene and Tropical Medicine and WHO. Written consent was obtained from all respondents following discussion of the study and provision of an information sheet.

1 World Health Organization. Commission on Macroeconomics and Health. Macroeconomics and health: investing in health for economic development. Geneva, Switzerland: WHO, 2001.

2 Trouiller P, Olliaro P, Torreele E, Orbinski J, Laing R, Ford N. Drug development for neglected diseases: a deficient market and a public-health policy failure. Lancet 2002;359:2188-94.

3 World Health Organization. Priority medicines for Europe and the world. Geneva, Switzerland: WHO, 2004

4 Olliaro P, Smith P. The European and developing countries clinical trials partnersip J HIV Ther $2004,9.53-6$.

partnership. J HIV Ther 2004;9:53-6.
United Nations. United Nations millennium declaration. United Nations General Assembly resolution 55/2. New York, NY: UN, 2000.
6 Duley L. Maternal mortality and hypertensive disorders of pregnancy in Africa, Asia, Latin America and the Caribbean. Br J Obstet Gynaecol Africa, Asia, Latin

7 World Health Organization. The world health report 2005. Make every mother and child count. Geneva, Switzerland: WHO, 2005.

8 Duley L, Gülmezoglu A, Henderson-Smart D. Magnesium sulphate and other anticonvulsants for women with pre-eclampsia. Cochrane Database Syst Rev 2003(2):CD000025.

9 Eclampsia Trial Collaborative Group. Which anticonvulsant for women with eclampsia? Evidence from the collaborative eclampsia trial. Lancet 1995;345:1455-63.

10 Magpie Trial Collaborative Group. Do women with pre-eclampsia, and their babies, benefit from magnesium sulphate? The magpie trial: a randomised placebo-controlled trial. Lancet 2002;359:1877-90.

11 World Health Organization. WHO model list of essential medicines. 13th edn. Geneva, Switzerland: WHO, 2003.

12 Aaserud M, Lewin S, Innvaer S, Paulsen E, Dahlgren A, Trommald M, et al. Translating research into policy in developing countries: a case study of magnesium sulphate for pre-eclampsia. BMC Health Serv Res 2005 (in press)

13 Sheth S, Chalmers I. Magnesium for preventing and treating eclampsia: time for international action. Lancet 2002;359:1872-3.

14 WHO/Unicef. Maternal mortality in 2000. Estimates developed by WHO, Unicef and UNFPA. Geneva, Switzerland: WHO, 2004.

15 Granja A, Machungo F, Gomes A, Bergstrom S, Brabin B. Malaria-related maternal mortality in urban Mozambique. Ann Trop Med Parasitol maternal morta

16 Ministry of Health and Child Welfare. Zimbabwe national health profile 2000. Harare: MoHCW (Epidemiology and Disease Control, National Health Information and Surveillance Units) in conjunction with the Central Statistical Office, 2000

17 Green J, Thorogood N. Qualitative methods for health research. London: Sage, 2004.

18 Kaplan WA, Laing R. Paying for pharmaceutical registration in developing countries. Health Policy Plan 2003;18:237-48.

19 Gravelle H, Rees R. Microeconomics. London: Prentice Hall, 2004.

20 Remarks by Governor John A Kitzhaber. States and provinces: creating a functional marketplace for prescription drugs, 11-12 Oct 2002, a functional marketplace for prescription drugs, 11-12 Oct 2002, Portland, Oregon. http://www.oregon.gov/DAS/OHPPR/ORRX/docs/
Governors_Conference_Presentations/Kitzhaber_speech_Drug_Conf_ Oct10_02_Final.pdf (accessed 16 May 2005).

\title{
Gaining a foothold: tackling poverty, gender inequality, and HIV in Africa
}

\author{
Julia C Kim, Charlotte H Watts
}

Over half of adults infected with HIV in Africa are female--but poverty and social structures still prevent many women from protecting themselves

The United Nations millennium development goals have set out specific targets for 2015, including commitments to reduce extreme poverty, increase women's empowerment, and reverse the spread of the HIV pandemic. In this respect, they clearly recognise what has been called the triple threat facing Africa: poverty, gender inequalities, and HIV and AIDS. ${ }^{1}$ Tackling these issues is clearly difficult, and many people have greeted these goals with a sense of scepticism and even futility. We describe why tackling poverty and gender inequalities is central to controlling the HIV pandemic in Africa and suggest how it might be achieved.

\section{Women and HIV}

Two years ago, the UN secretary general Kofi Annan declared that "AIDS has a woman's face." Echoing this statement, the Joint United Nations Programme on HIV and AIDS (UNAIDS) has highlighted women, girls, and HIV and AIDS as the theme for their most recent World AIDS Day campaign. Today, women account for nearly half the 40 million people living with HIV worldwide. In sub-Saharan Africa, $57 \%$ of adults with HIV are women, and young women aged
15 to 24 are more than three times as likely to be infected as young men. ${ }^{3}$

Contradictory analyses of Uganda's success in tackling HIV and AIDS have sparked debates over the relative prevention merits of promoting condoms, sexual fidelity, or abstinence. The United States has increased its funding for abstinence-only strategies, while the Catholic Church has questioned the efficacy of condoms, raising concerns about the influence of ideological or religious perspectives in shaping global priorities for prevention. ${ }^{4}$ Yet a larger question remains. Regardless of their point of emphasis, why are HIV prevention efforts continuing to fail women and girls?

The prevention messages, whether urging women to abstain, be faithful, or use condoms, often fail to reflect the reality of women's lives and, in particular, the broader social forces that contribute to their risk. In settings where limited educational or economic opportunities exist, pressures of poverty lead women and girls to trade sex for survival. Where women have low status and financial autonomy, and depend on their partners for support, abstaining from sex or negotiating use of condoms are simply not realistic options. Moreover, physical and sexual violence affect women's ability to
Rural AIDS and Development Action Research Programme, School of Public Health, University of the Witwatersrand, PO Box 2, Acornhoek 1360 , South Africa Julia C Kim senior researcher

Health Policy Unit, London School of Hygiene and Tropical Medicine, London

WC1E 7HT

Charlotte H Watts head

Correspondence to: J C Kim jkim@soft.co.za

BMJ 2005;331:769-72 


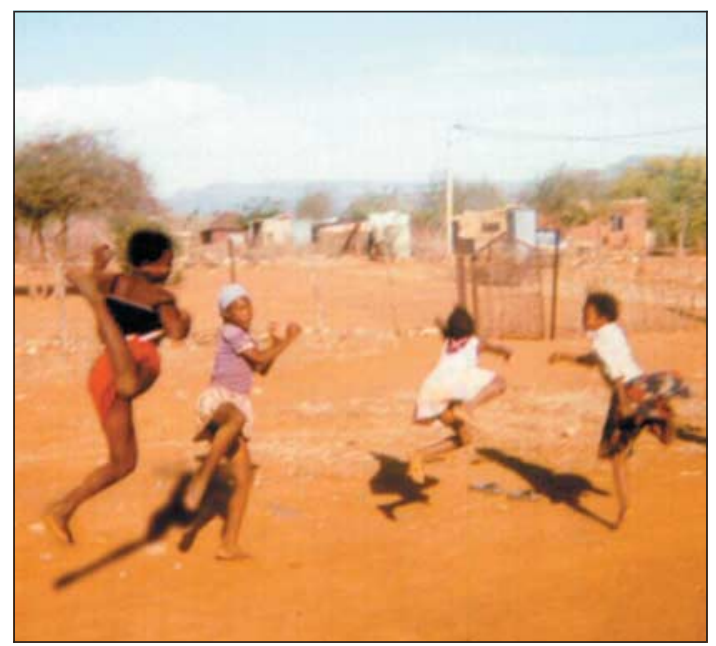

Women in an intervention for AIDS and gender equity programme in South Africa used disposable cameras to help them "think gender"

protect themselves from infection. Refusing sex, inquiring about other partners, or suggesting condom use have all been described as triggers for intimate partner violence; yet all are intimately connected to the behavioural cornerstones of HIV prevention. ${ }^{5}$

Although the primary prevention messages remain important, and access to existing and new female controlled prevention methods, such as the female condom or microbicides, should be a priority. Yet far more attention must be devoted to promoting the wider social and economic interventions that might reduce women's vulnerability to HIV. The UN General Assembly special session on HIV and AIDS made the gender dimensions of the epidemic explicit. In 2001, delegates from over 180 countries stressed that gender equality and the empowerment of women will be critical in controlling the HIV pandemic. ${ }^{6}$

How well equipped is the public health community to respond to this call? Certainly, we have seen some important successes in decreasing infection rates among circumscribed groups such as gay men in the United States or commercial sex workers in Thailand..$^{78}$ To date, however, our traditional focus on health sector interventions and high risk groups has had limited impact on the generalised epidemics now facing much of Africa. ${ }^{9}$

\section{Getting back to basics}

In an attempt to expand the scope of intervention strategies for HIV and AIDS, the concept of mainstreaming AIDS in development is gaining currency. The concept seeks to strengthen the ways in which existing development processes tackle both the causes and the consequences of HIV and AIDS..$^{10}$ The range of actors may be broad, reaching beyond the health sector to include the judiciary, government ministries, industry, and non-governmental organisations. In relation to women's empowerment, mainstreaming HIV challenges sectors to examine how their core activities address the status of women and, in so doing, their risk of HIV infection.

For example, when a woman's right to own, inherit, and control property is limited by customary or statutory laws, the potential role of legal reforms as a part of a comprehensive response to HIV cannot be ignored. In South Africa, the Customary Marriages Act now mandates that a woman no longer becomes the property of her husband's family when he dies, thus safeguarding her independence and entitlement to household assets. Similarly, in Kenya, the government has recently pledged to promote gender equality, creating a ministry of gender and a new constitution protecting women's property rights. Although not explicitly linked to HIV and AIDS, such systematic efforts to increase women's economic, social, and political empowerment must be supported as key components of a comprehensive AIDS strategy. ${ }^{11}$

\section{Microfinance initiatives}

By improving access to credit and savings services, microfinance initiatives seek to provide business skills and income generating opportunities for poor women who are excluded from formal financial services and markets. In 1998, the Microcredit Summit Campaign reported reaching 2.1 million impoverished African families. The most recent report notes that by 2003 , microfinance initiatives had reached an estimated 6.4 million clients in Africa, showing a potential to reduce household poverty and improve security of livelihood among people in extreme poverty. ${ }^{12}$ Though far from being a solution to poverty, such programmes can enable some of the most vulnerable women to "at least gain a foothold on the bottom rung," from which they might begin to progress. ${ }^{13}$

Alongside the economic benefits, such initiatives may enhance autonomy among participants. The newly acquired economic and business skills translate into improvements in self esteem and self confidence, larger social networks, and wider control over household decision making. ${ }^{14}$ Moreover, evaluations of programmes such as the Grameen Bank and Bangladesh Rural Advancement Committee have shown an increase in acceptance and use of contraceptives, suggesting that women who contribute money and participate in family decisions have more control over sexual and reproductive health decisions. ${ }^{15}{ }^{16}$ Such programmes have also shown a potential to reduce the incidence of domestic violence, primarily by channelling resources through women, organising women into solidarity groups, and making women's lives more public. ${ }^{17}$

\section{A foothold but not the whole ladder}

At the same time, it is important to acknowledge that the links between microfinance and empowerment are complex. Some researchers have pointed out that although targeting women for microfinance has been promoted as a means for both increasing cost efficiency (because women have higher repayment rates) and more effective alleviation of poverty (because they prioritise expenditure on family welfare), channelling resources to women may have the potential to exacerbate gender related tensions in the household. Others have suggested that mobilising a critical mass of participants and shifting social norms may be necessary before domestic violence is reduced and women are more broadly empowered. ${ }^{17} 18$

There is also increasing recognition that empowering individuals requires strengthening access to 
resources and building individuals' ability to use those resources, make decisions, and take leadership. Hence, some authors have suggested that adding a training or capacity building component to the financial aspect of microfinance programmes may be important in catalysing the broader benefits of increased access to economic resources ${ }^{1920}$ and potentially diminishing the risk of gender related conflict. ${ }^{17}{ }^{21}$

Microfinance initiatives in countries such as Uganda, Rwanda, Ghana, Togo, Zambia, Zimbabwe, and South Africa are starting to include education about HIV as part of the programme..$^{22}$ The approach can be successful even in areas with a high prevalence of HIV, where households receiving loans are facing HIV related illness and death. In Uganda, for example, the Foundation for International Community Assistance has recovered $100 \%$ of its loans while simultaneously working to promote condoms and educate its clients about safer sex. ${ }^{24}$

\section{Broadening the scope of interventions}

Many opportunities may exist for integrating HIV and gender issues into broader development strategies. In Kenya, an intervention that provided female sex workers with education on fertility and HIV and AIDS alongside business training and start-up funds has led to reductions in the numbers of sexual partners and increases in condom use. ${ }^{25}$ In Zimbabwe, the Rusape Girls Empowerment Village is attempting to strengthen the development of disadvantaged rural girls by combining HIV education with increased access to information and communication technology through a village computer laboratory ${ }^{26}$ Such broad interventions have the potential to generate multiple benefits. The Tostan development programme in Senegal began with the aim of improving literacy and awareness of human rights among women, and ended up mobilising communities around women's reproductive health and rights, including public declarations against female genital cutting in 31 villages. ${ }^{27}$

Greater documentation and evaluation of such approaches is needed. A few initiatives are beginning to explore the impact of "structural level interventions" that aim to influence the economic or social contexts in which risk occurs. In rural South Africa we are using a cluster randomised design to explore the effect on biological and behavioural outcomes relating to HIV and AIDS and violence against women of a programme that combines microfinance with training on gender issues, HIV, and violence. ${ }^{22} 28$

\section{Where do we begin?}

Attempting to tackle immense and complex issues such as poverty and gender inequality may seem overwhelming. Yet there are signs that global leaders may be finally recognising the need to couple resources for AIDS specific interventions and technologies with explicit commitments aimed at reducing poverty. ${ }^{29}$ At the same time, there is a need to develop and test practical intervention strategies that acknowledge the importance of addressing women's economic and social empowerment, while mainstreaming AIDS within these broader development goals.

\section{Summary points}

Current strategies to change HIV risk behaviour continue to fail women and girls in Africa

Structural interventions that aim to increase women's economic, social, and political empowerment are key components of a comprehensive AIDS strategy

Economic development initiatives (such as microfinance) may present a strategic entry point for addressing the relations between HIV, poverty, and gender inequality

Ultimately, such local, programmatic approaches need to intersect with national and international polices to produce systemic changes in women's status and wellbeing

The programmatic approaches we have described suggest an important entry point for tackling HIV in the context of the immediate realities that women face. At the same time, however, they need to intersect with macro level influences that carry the potential for far more sustained and systemic changes in women's status and wellbeing. Too often, the impact of scaling-up or replicating locally successful models continues to be constrained by a lack of articulation and engagement with broader structures and forces. How might the wider benefits of microfinance programmes be influenced, by the effect of global agricultural and trade policies on rural livelihoods or the role of multinational corporations in shaping women's access to labour markets? Ultimately, intervention strategies need to be linked to the broader globalisation processes that condition and constrain local possibilities. ${ }^{30}$

This year has been declared the UN international year of microcredit. To date, the campaign seems to be on track with its goal of reaching 100 million of the world's poorest families by the end of the year, offering much needed encouragement in meeting the challenge of the millennium development goals. ${ }^{12}$ We wait for world leaders to couple rhetoric with action and take substantial steps to ensure trade justice, cancel poor countries' unpayable debts, and increase aid to the current target of $0.7 \%$ of their national income. In the meantime, those working on the ground will continue to show up every morning, despite the dire statistics, in pursuit of that most precious commodity needed for Africa and the international communityhope.

Contributors and sources: JCK is a specialist in gender and health and has international research experience relating to gender based violence and HIV and AIDS, and is a research fellow at the London School of Hygiene and tropical Medicine. CHW has written widely on issues relating to microbicides, HIV, and violence against women, and is senior lecturer in epidemiology and health policy. Both have an interest in structural interventions, and are involved in the IMAGE study in South Africa. JCK and CHW contributed original conceptualisation, analysis, and literature review for this article.

Competing interests: None declared. 
1 UNAIDS, UN Population Fund, UN Development Fund for Women Women and HIV/AIDS: confromting the crisis. New York: UN Population Fund, 2004. www.unfpa.org/hiv/women/report/index.htm (accessed 1 Sep 2005)

2 Annan K. In Africa, AIDS has a woman's face. New York Times 2002 Dec 29.

UNAIDS. Fourth report on the global AIDS epidemic. Geneva: UNAIDS 2004.

Cohen S. Beyond slogans: Lessons from Uganda's experience with ABC and HIV/AIDS. Reprod Health Matters 2004;12:132-5.

5 Gupta GR. How men's power over women fuels the HIV epidemic. BMJ 2002;324:183-4.

6 United Nations General Assembly Special Session on HIV/AIDS. Declaration of Commitment on HIV/AIDS, 2001. www.unaids.org/html/pub/ publications/irc-pub03/AIDSDeclaration_en_pdf/ publications/irc-pub03/AIDSDeclaration_en_pdf/

AIDSDeclaration_en_pdf_l.jpg (accessed 1 Sep 2005).
Rojanapithayakorn W, Hanenberg R. The $100 \%$ condom program in Thailand. AIDS 1996;10:1-7

8 Winkelstein W, Wiley JA, Padian NS, Samuel M, Shiboski S, Ascher MS, et al. The San Francisco men's health study: continued decline in HIV seroconversion rates among homosexual/bisexual men. Am J Public Health $1988 ; 78: 1472-4$

9 Sumartojo E, Doll L, Holtgrave D, Gayle HD, Merson MH. Enriching the mix: incorporating structural factors into HIV prevention. AIDS 2000;14(suppl 1):S1-2

10 Holden S. Mainstreaming HIV/AIDS in development and humanitarian programmes. Oxford: Oxfam GB, 2004

11 Human Rights Watch. Double standards:women's property rights violations in Kenya. New York: Human Rights Watch, 2003.

12 Daley-Harris S. State of the microcredit summit campaign report 2004 Washington, DC: Microcredit Summit Campaign, 2004. www.microcreditsummit.org/pubs/reports/socr/2004/SOCR04.pdf (accessed 1 Sep 2005)

13 Sachs J. The end of poverty: How we can make it happen in our lifetime. London: Penguin, 2005.

14 Cheston S, Kuhn L. Empowering women through microfinance. In: Harris SD, ed. Pathways out of poverty: innovations in microfinance for the poorest families. Bloomfield: CT: Kumarian Press, 2002:167-228.

15 UNAIDS. Gender and HIV/AIDS: taking stock of research and programmes. Geneva: UNAIDS, 1999.

16 Schuler S, Hashemi S, Riley A. The influence of women's changing roles and status in Bangladesh's fertility transition: evidence from a study of credit programmes and contraceptive use. World Development 1997:25:563-75.

17 Schuler SR, Hashemi SM, Riley AP, Akhter S. Credit programs, patriarchy, and men's violence against women in rural Bangladesh. Soc Sc Med 1996;43:1729-42

18 Goetz AM, Gupta SR. Who takes the credit? Power and control over loan use in rural credit programs in Bangladesh. World Development 1996;24:45-63.

19 Population Council. Power in sexual relationships: an opening dialogue among reproductive health professionals. New York: Population Council, 2001.

20 Mayoux L. Women's empowerment and micro-finance:programmes, approaches evidence, and ways forward. Milton Keynes: Open University, 1998. (Development policy and practice working paper 41.)

$21 \mathrm{Ahmed} \mathrm{SM.} \mathrm{Intimate} \mathrm{partner} \mathrm{violence} \mathrm{against} \mathrm{women:} \mathrm{experiences} \mathrm{from}$ a woman-focused development programme in Matlab, Bangladesh. $J$ Health Popul Nutr 2005;23:95-101.

22 Pronyk PM, Kim JC, Hargreaves JR, Makhubele MB, Morison LA, Watts $\mathrm{CH}$, et al. Microfinance and HIV prevention: perspectives and emerging lessons from rural South Africa. Small Enterprise Development (in press).

23 Microcredit Summit Campaign. African microenterprise AIDS initiative. http://www.microcreditsummit.org/press/Africanmicro.htm (accessed 2 Sep 2005).

24 Microcredit Summit Campaign. What about the other Africa? http:// www.microcreditsummit.org/press/other.htm (accessed 2 Sep 2005).

25 Kirubi M, Ngugi EN, Kamau P, Nyanbola L, Ronald A. The impact of social, economic and sexual empowerment:commercial sex workers [abstract 447D].X international conference on AIDS, Yokohama, 1994.

26 Communication Initiative. Programme experiences: Rusape girls empowerment village, Zimbabwe. www.comminit.com/experiences/pds22004 experiences-515.html (accessed 2 Sep 2005).

27 Population Council. Tostan breakthrough in Senegal: ending female genital cutting. Dakar: Population Council, 1999.

28 Hargreaves J, Pronyk P, Kim J, Makhubele M, Watts C, Morison L, et al The intervention with microfinance for AIDS and gender equity study (IMAGE): www.wits.ac.za/radar/IMAGE studyhtm

29 BBC News. Brown calls for 5.5 billion pound AIDS fund. BBC News World Edition 2005 Jan 13. http://news.bbc.co.uk/2/hi/uk_news/politics/ $4170531 \mathrm{stm}$ (accessed 2 Sep 2005).

30 Sanders D, Labonte R, Baum F, Chopra M. Making research matter: a civil society perspective on health research. Bull World Health Org 2004;82:757-63.

\title{
Patients' readiness to start highly active antiretroviral treatment for HIV
}

\author{
Hirut T Gebrekristos, Koleka P Mlisana, Quarraisha Abdool Karim
}

Assessing whether patients are ready to start antiretroviral treatment may improve HIV prevention and treatment outcomes

Centre for AIDS Programme of Research in South Africa (CAPRISA) Nelson R Mandela, School of Medicin Durban, South Africa

Hirut T

Gebrekristos research fellow Koleka P Mlisana project director

Quarraisha Abdool

Karim

associate professor

Correspondence to: H T Gebrekristos hgebrekr@jhsph.edu

BMJ 2005;331:772-5
Initiatives to increase access to antiretroviral treatment in resource constrained settings are growing, but the scale and magnitude of the HIV epidemic in these settings raises a number of operational and ethical challenges. Most people infected with HIV are unaware of their status, and people who are aware of their status fear stigmatisation and discrimination. Key themes about access to treatment include who gets treatment, when is the best time to start treatment, and how to ensure therapeutic success.

Numerous guidelines for treatment have been developed nationally and internationally. One concern is how initiation of antiretroviral treatment should relate to patients' readiness and commitment. Although patients' readiness is emphasised as a requirement for starting treatment in several guidelines,${ }^{1-4}$ the guidelines are neither clear nor in consensus about what constitutes readiness and how this readiness should be assessed. Given this ambiguity, readiness may be used to ration resources, particularly in resource poor settings, in which access to antiretrovirals is currently gaining support. The potential of using readiness to improve HIV prevention and care outcomes, however, mandates that we closely examine the use of readiness for starting highly active antiretroviral treatment (HAART).

Studies about assessing patients' readiness for starting HAART or the impact of this on therapeutic success are few. One small study found that lack of readiness resulted in interrupted treatment and risky sexual behaviour; therefore, readiness for treatment may help care givers to make decisions about when to start treatment with antiretrovirals for each patient. ${ }^{5}$ The potential importance of treatment readiness for therapeutic success is why a more structured and systematic approach to evaluating readiness is needed. In addition, a systematic evaluation of the use of treatment readiness becomes particularly important in settings where "readiness" may be misused to ration resources. Rigorously collected data will be critical in shaping appropriate interventions that go beyond anecdotal notions that readiness is important in determining when to start HAART. 